\title{
REFLECTIONS OF YOUNG ADULTS ON THE LOSS OF A PARENT IN ADOLESCENCE
}

\section{Eva Apelian and Olena Nesteruk}

\begin{abstract}
This study explores the reflections of young adults on the experience of parental loss in adolescence. Participants were recruited through snowball sampling and personal connections from Montreal and New Jersey. Personal interviews based on in-depth, open-ended questions were used to examine how parentally bereaved children and their families were affected in the short term and into early adulthood. The use of resources, coping strategies helpful to the participants, and adaptation to the death were also explored. The findings of the study are discussed through the lens of the Double ABC-X model of family stress and adaptation. Four themes emerged from the data analysis: (a) pile-up of stressors aggravates grieving; (b) benefits of social support; (c) coping strategies used by the participants; (d) adaptation to the loss of a parent - personal growth and maturation. Implications for future research and practitioners working with this population are discussed.
\end{abstract}

Keywords: parentally bereaved, adolescents, coping, grief, qualitative, family stress

Eva Apelian M.S. (the corresponding author) is a graduate of the Department of Family Science and Human Development, Montclair State University, Montclair, NJ 07043, USA. Email: eva.apelian@gmail.com

Olena Nesteruk Ph.D. is an Associate Professor in the Department of Family Science and Human Development, Montclair State University, 1 Normal Ave., 4036 University Hall, Montclair, NJ 07043, USA. Email: nesteruko@,mail.montclair.edu 
Parents usually die before their children, but in some cases bereavement takes place at an early age. The experience of losing a parent is especially challenging to accept and grieve when it occurs prematurely; such a loss strongly impacts children's lives (Lawrence, Jeglic, Matthews, \& Pepper, 2005; Raveis, Siegel, \& Karus, 1999). There are approximately 153 million children around the world who have lost one or both parents (Gimenez, Chou, Liu, \& Liu, 2013). In the United States, 2.5 million children under the age of 18 have experienced the death of a parent (Koblenz, 2015). In Canada in 2011, less than $1 \%$ of children aged 0 to 14 had lost one parent to death; there were 29,600 foster children aged 14 who had lost both parents (Statistics Canada, 2015). Although in Canada in 2016, nearly one fifth (19.2\%) of children aged 0 to 14 were part of a lone-parent family - a family created following a separation, a divorce, or the death of a parent (Statistics Canada, 2016) — death is not the main cause of lone-parent families.

It is important to learn about and understand children's grief experiences, as unresolved grief may lead to severe repercussions later in life such as psychiatric issues, health problems, and depression (Lawrence et al., 2005; McClatchey \& Wimmer, 2012). For example, early life stressors such as early parental death are known to contribute to suicide, which was the tenth leading cause of death among youth in the United States in 2011 (Hollingshaus \& Smith, 2015). In Canada, 24\% of deaths among people aged 15 to 24 years of age are attributed to suicide; a common risk factor for suicide is a significant loss, such as the death of a parent (MediResource, 2017).

Although the death of a parent may have adverse repercussions (Koblenz, 2015; Saler \& Skolnick, 1992), it can also lead to children becoming more resilient (Greeff \& Human, 2004; Hope \& Hodge, 2006; Raveis et al., 1999). The term resilience is used in multiple ways, however; it is argued that it often occurs in the presence of adversity (Masten \& Powell, 2003; Ungar, 2008). In one usage, resilience is a trait of children who grow up successfully despite being faced with disadvantaged circumstances during childhood (Ungar, 2008). Second, resilience can refer to capability when subject to stress (Ungar, 2008): resilient children may show proficiency despite dealing with threats to their well-being. Third, resilience can indicate positive functioning and an effective recovery post-trauma (Ungar, 2008). Resilience is associated with factors that support human health and promote psychological health (Greeff \& Human, 2004). Studies show that resilient families perceive crises as manageable challenges rather than devastating tragedies (Greeff \& Human, 2004). It is therefore crucial to study the effects of parental death on children in order to alleviate severe health and psychological issues and promote resiliency.

The rationale for the present study is to further understand the overall experiences of young adults grieving the death of one of their parents. This subject is not discussed enough in everyday life and has not received much attention in the scholarly literature (Koblenz, 2015; LaFreniere \& Cain, 2015). The effects of death and the grieving process are unique to each individual; thus this study further informs how individuals cope with the death of a parent. 
International Journal of Child, Youth and Family Studies (2017) 8(3-4): 79-100

\section{Literature Review}

There are many factors that affect a child's grief process after the death of a parent, such as the child's family, the deceased parent's gender, the gender of the child, and the circumstances of the death (Osterweis as cited in Raveis et al., 1999). For example, a child is less likely to develop problems after the death if the surviving parent is available and supportive and if the child has adequate social support (Silverman \& Worden, 1992). Among the factors that contribute to successful grieving, researchers identified support and communication from various family members, peers, and therapists; the stability of the child's environment after the death; and the circumstances of the death (Greeff \& Human, 2004; Hope \& Hodge, 2006; Koblenz, 2015; Silverman \& Worden, 1992).

\section{Immediate Effects on Children Following Parental Death}

Daily and lifestyle changes: After the loss of a parent, a child may face immediate effects such as health and psychological issues (Raveis et al., 1999; Silverman \& Worden, 1992), changes in routine and a disruption in the stability of their environment (Silverman \& Worden, 1992; Worden, 1996). These short-term effects may adversely impact the child and make grieving a longer and more difficult process. Families that experience loss may be faced with many daily changes such as relocation and change of schools; decrease in surviving parent's emotional availability; arguments and disruption in communication; increase in household chores, especially after the death of a mother; possible need for employment for adolescents; and changes in bedtimes and mealtimes (LaFreniere \& Cain, 2015; McClatchey \& Wimmer, 2012; Raveis et al., 1999; Worden, 1996). Adolescent girls who have lost a mother may take on a maternal role and become the family's caretaker, a burdensome responsibility at an early age (Edelman, 1994).

A family's financial situation after the death of a parent affects the family's grieving process. If financial resources have been drained due to medical bills, or if the deceased parent was the primary breadwinner, this can be extremely stressful for the remaining family members (Greeff \& Human, 2004). Children from wealthy families were found to experience fewer sleep disturbances after the death of their parent, concentrate better in school, and have fewer learning difficulties than children from less affluent families (Greeff \& Human, 2004; Raveis et al., 1999). The more the daily environment is disrupted after the death, the more difficult it is for children to adjust well (LaFreniere \& Cain, 2015; Silverman \& Worden, 1992).

Health and psychological issues: Following the death of a parent, children may experience distress, anxiety, depression, and difficulty focusing in school (Raveis et al., 1999; Silverman \& Worden, 1992). Depression is very common among children after the death of a parent: about half of bereaved children become depressed in the year following their parent's death, and 16\% remain depressed after the year has passed (Pfeffer, Jiang, Kakuma, Hwang, \& Metsch, 2002). Anxiety disorders are also common, especially among younger children who lack the developmental maturity to understand and cope with the changes after the death (Jacobs et al., 1990; Raveis et al., 1999). 
International Journal of Child, Youth and Family Studies (2017) 8(3-4): 79-100

\section{The Role of Communication and Support after Parental Death}

The post-death family environment can significantly influence how well a child will adapt and adjust to parental death (Hope \& Hodge, 2006; Koblenz, 2015). Children and adolescents need to feel supported and taken care of by their surviving parent after the other's death. A stable environment, a similar routine to the one before the parent died, and open communication and support from the surviving parent can allow the child to grieve in a healthy way (Bugge, Darbyshire, Rokholt, Haugstvedt, \& Helseth, 2014; LaFreniere \& Cain, 2015; Saldinger, Porterfield, \& Cain, 2004).

Surviving parent: The surviving parent's adjustment to the death of a spouse plays an important role in the children's ability to adapt to the death of a parent; they must model the grieving process for their children (Bugge et al., 2014; Hope \& Hodge, 2006). Parents must find a way to be emotionally available for their children while dealing with the loss of a spouse at the same time. It is therefore essential for the parent to find his or her own support system (Hope \& Hodge, 2006). Children need to feel emotionally supported by their surviving parent and be able to openly communicate about their deceased parent (Koblenz, 2015; Hope \& Hodge, 2006). Sharing feelings and talking about the deceased parent allows the child to process grief in a healthier manner and thus adapt more successfully to the loss (Saldinger et al., 2004). Children who are able to openly communicate with their surviving parent about the deceased parent and about their sorrow surrounding the death have a lower risk of developing depression in adulthood (Saler \& Skolnick, 1992).

Siblings: Research on sibling relationships in parentally bereaved families has been contradictory, with some studies showing the benefit of having a sibling to share the tragic experience with (Hurd, 2002; Mack, 2004), and others showing the burden of having a sibling after the death of a parent (Connidis, 1992; Scharlach \& Fredriksen, 1993). When the death of a parent occurs in childhood, the effect on siblings can be complicated, as some sibling relationships will experience positive outcomes while others will experience negative ones (Ross \& Milgram, 1982). Hurd (2002) found that siblings can assist each other in grieving in a healthy way and avoiding depression; thus they become a very strong source of support, especially when the surviving parent is too preoccupied with his or her own grief. Parental death may result in siblings becoming closer and strengthening their sibling bonds (Hurd, 2002; Mack, 2004); however, the death may also create distance between the siblings, especially if the deceased parent occupied the role of kinkeeper in the family (Scharlach \& Fredriksen, 1993).

Extended relatives: Extended family members can be an important support system for bereaved children and adolescents by providing "practical assistance, companionship, and a sense of security and solidarity, which can assist the family to adjust to the loss" (Greeff \& Human, 2004, p. 37). Relatives such as grandparents, cousins, aunts, and uncles may provide an outlet for grief that makes it easier for a bereaved child to cope with the loss of a parent (Greeff \& Human, 
International Journal of Child, Youth and Family Studies (2017) 8(3-4): 79-100

2004; Eppler, 2008). Families who lack a such a supportive extended network are not able to cope as well with the death (Walsh \& McGoldrick, 2004).

Peer support: A supportive social network of siblings and friends can be effective in helping the child grieve (Silverman \& Worden, 1992). Children, adolescents, and young adults are involved with other peers and friends on a daily basis; these relationships provide opportunities for grieving youth to find support in their peers (LaFreniere \& Cain, 2015). For some adolescents, peers were the most helpful source of emotional support after the loss of their parent: time spent with friends allowed them to feel normal and less isolated (Dopp \& Cain, 2012; Gray, 1989). Parentally bereaved adolescents with good quality peer and romantic relationships report fewer depressive symptoms (Schoenfelder, Sandler, Wolchik, \& MacKinnon, 2011). Grief camps can be a helpful resource for parentally bereaved children and adolescents, who can spend time with other mourning children and relate to each other (Koblenz, 2015; McClatchey \& Wimmer, 2012). Being able to share their feelings with other children who had similar experiences allows children to feel more understood and less alone in their grief.

\section{Coping Strategies}

Coping styles influence the well-being of bereaved individuals and their adaptation to the death of a parent (Howell, Shapiro, Layne, \& Kaplow, 2015). Lazarus and Folkman (as cited in Lawrence et al., 2005) identified three coping styles: active/approach, support seeking, and avoidant. An individual with an active/approach coping style acknowledges that the death happened and finds ways to deal with it (Lawrence et al., 2005). Bereaved adolescents who used this style of coping were found to experience fewer depressive symptoms than adolescents who used other types of coping strategy (Herman-Stahl, Stemmler, \& Peterson, 1995). Individuals using the avoidant coping style do not acknowledge the death, instead using strategies to avoid thinking about the death and to try to focus on positive things in their lives (Glyshaw, Cohen, \& Towbes, 1989). Non-acknowledgment of the death may lead to psychological distress later in life (Kaplow, Gipson, Horwitz, Burch, \& King, 2013). An individual who uses a support-seeking coping style reaches out to peers, friends, and family for support and comfort (Lawrence et al., 2005). This coping strategy is associated with positive outcomes for the bereaved.

\section{Long-Term Effects on Children Following Parental Death}

In addition to the short-term effects, the premature death of a parent may also have longterm effects on the children. Much research in the death and bereavement area has focused on the immediate and short-term effects of losing a parent, while the lifelong process of coping with the death of a parent has received limited attention.

Milestone events: Milestone events and transitions may trigger a grief response in those who have lost a parent. For example, entering or graduating from high school, applying for college, or experiencing a first romantic relationship are events that may be difficult for children who no longer have one of their parents (Biank \& Werner-Lin, 2011). Other milestone events, such as 
graduating from college, getting married, and becoming a parent, may regenerate feelings of grief as well (Raveis et al., 1999). To date, very little research has been conducted on the impact of major life events on parentally bereaved children and adolescents, although these milestone events may in fact have a substantial impact (Biank \& Werner-Lin, 2011; Raveis et al., 1999).

The death of a parent has a multitude of effects on bereaved young adults; the road to adaptation is complex and varies among individuals. There is a lack of studies that explore the perspectives of young adults reflecting on the death of a parent and how it has affected them. We also need to know more about social and familial supports that promote youths' positive adaptation to parental loss, and the role of milestone events in potentially triggering grief responses in bereaved young adults.

\section{Current Study}

The present study seeks to address the gap in the literature on the loss of a parent in adolescence and related grief and adaptation experiences. The purpose of the present study is to give a voice to parentally bereaved young adults and to explore their reflections on coping with grief. Specifically, this study seeks to answer the following questions: How did parental death affect surviving adolescents both in the short term and into early adulthood? What resources and coping strategies did parentally bereaved children use and how have they adapted to this loss? Death is a subject that is not usually openly discussed, especially at a younger age, and therefore it is crucial to build a better understanding of the path leading to positive adaptation in order to provide more pertinent help to bereaved adolescents and young adults.

\section{Theoretical Framework}

Phenomenology guided the researchers in investigating the lived experiences of young adults in relation to the phenomena of parental loss, grief, and adaptation (Creswell, 2013; Daly, 2007). Consistent with the phenomenological approach, we relied on in-depth interviews with open-ended questions to elicit detailed descriptions of each participant's reality and the meanings they bring to it (Daly, 2007). During the data analysis process, as we attempted to make sense of the phenomena and discussed emerging concepts and themes, we realized that they fit well with the Double ABC-X model of family stress and adaptation, as developed by McCubbin and Patterson (1983) from Hill's (1958) original ABC-X model. Thus, we decided to use the Double ABC-X model and theoretical framework of family stress to further examine thematic concepts and build a coherent interpretation of the data.

The original ABC-X model of family stress, as developed by Hill (1958), focused on a family's reaction to a particular stressor event (A), their perceptions of the event $(C)$, and their ability to adapt to the situation based on the resources available (B). Hill's model postulates that there is a crisis-provoking event (A Factor). A stressor is not necessarily an event that is traumatic; rather, it is an event that creates a change in family dynamics and has a potential to destabilize the family. The stressor event then interacts with the family's access to and use of resources (B Factor), 
such as individual, familial, and community resources, all of which may help a family deal with the crisis. The family's ability to cope with the stressor (A) also depends on the family's definition of the event (C Factor). This is the way a family unit interprets and perceives the event it is faced with. The perception (C) of the event (A), along with availability and use of resources (B), will have an impact on the family's ability to adapt to the situation at hand. Factors A, B, and C all play a role in whether or not a family will fall into crisis after being exposed to the stressor event (Boss, 2002).

Families often have to deal with a pile-up of additional stressors after an initial stressor event occurs. The Double ABC-X model of family stress and adaptation by McCubbin and Patterson (1983) accounts for that complexity and includes the components that accompany family adaptation post-crisis. The pile-up of demands (aA) refers to the multiple stressors a family may experience after the initial stressor event occurs (McCubbin \& Patterson, 1983). Families also have resources $(\mathrm{bB})$ which allow them to meet their needs and demands following a crisis, including some resources, such as health professionals, that may become available after the event. McCubbin and Patterson (1983) identified three kinds of resources:

- Family members' personal resources - money, education, health, personality characteristics, and self-esteem;

- Family system's internal resources - the family's ability to communicate and their adaptability to the situation; and

- Social support - support from social networks such as extended relatives and the community.

Families give new meaning to their situation post-crisis; the way they perceive (cC) the crisis $(\mathrm{X})$ will affect how they adapt to the situation. Individuals and families may use various coping strategies to adjust to the crisis, such as avoidance, elimination (a family's effort to remove the stressor or change its meaning), and assimilation (McCubbin \& Patterson, 1983).

The final phase of the Double ABC-X model is adjustment, when families make changes to their existing family structure in order to adapt to the crisis. This restructuring may include modifying roles, rules, goals, and patterns of interaction (McCubbin \& Patterson, 1983). The outcome of the crisis is based on the multiple factors $(\mathrm{aA}, \mathrm{bB}, \mathrm{cC})$ that interact with one another and result in the family functioning on a continuum between positive adaptation, called bonadaptation, and negative adaptation, or maladaptation (McCubbin \& Patterson, 1983).

Compared with the original ABC-X model, the Double ABC-X model is more effective in explaining a family's reaction to a traumatic life event when multiple stressors are occurring (McCubbin \& Patterson, 1983). Using the Double ABC-X model, the present study will discuss the effects of a particular type of crisis - parental loss during adolescence — and what resources and coping strategies were helpful, from the perspective of young adult survivors. 
International Journal of Child, Youth and Family Studies (2017) 8(3-4): 79-100

\section{Methodology}

Guided by a phenomenological approach, we aimed to examine participants' lived experiences with loss, grief, and adaptation through their eyes (Creswell, 2013; Daly, 2007). In order to gain an understanding of the parentally bereaved young adults' adaptations, a qualitative research design with in-depth personal interviews was used.

\section{Recruitment and Interview Procedures}

After institutional review board approval was obtained, participants were recruited through personal connections of the first author and using snowball sampling. Inclusion criteria required that: (a) participants were young adults between the ages of 18 and 30; (b) participants had lost a parent after the age of eight (otherwise they would have limited memories of the parent); and, (c) at least two years had passed since death (to allow some time for coping).

Prior to the interviews, participants filled out a consent form and a demographic information sheet. Face-to-face semi-structured interviews lasted about an hour and took place in the home of either the first author or the participant. The interview guide consisted of 14 questions pertaining to family relationships before and after the death, support from social networks, daily life changes after the death, and so on (see Appendix). The interview questions were created prior to the use of the Double ABC-X model. The order of the questions and the wording were altered as needed during the interview; follow-up questions asking for details or clarification were used. Interviews were audiotaped and later transcribed verbatim. Field notes with observations about interview sessions were written.

Conducting in-depth interviews on such a sensitive topic requires trust between the researcher and study participants. The first author's "insider" status as a parentally bereaved adolescent was shared with the participants, which facilitated positive rapport during the recruitment and interview process.

\section{Description of Participants}

Eleven participants who fit the recruitment criteria were interviewed for this study. Eight of the participants were recruited in Montreal, Canada, and three in northern New Jersey, United States. Five participants were female and six were male, with a mean age of 27 (range 18-34). The average age of the participants at the time of the parental death was 16.4 (13-20); an average of eight years had passed since the death (1-17). Although the inclusion criteria established at the beginning of the study set a maximum age of 30 years for participants and the passage of at least two years since the death of a parent, we expanded these parameters slightly to include three participants in their early thirties and one participant who had lost a parent less than two years ago. Considering the difficulty of finding and recruiting individuals for research on such a sensitive topic, it was decided that these were acceptable deviations from the original criteria for participation. Six participants had experienced loss of a mother and five had lost a father. For seven of the participants the death of a parent had been expected due to a long-term illness (e.g., cancer, 
International Journal of Child, Youth and Family Studies (2017) 8(3-4): 79-100

lung disease); for four of the participants the death was sudden and unexpected (e.g., aortic aneurysm, heart attack). Ten of the participants had one or more siblings; one participant was an only child. All of the participants were either currently in college or had completed a bachelor's degree and were employed.

\section{Data Analysis}

Following transcription, interviews and demographic data for each participant were organized into files and analyzed using a phenomenological approach (Merriam \& Tisdell, 2016). Phenomenology directs researchers to explore the world from the perspective of the participants in order to develop an in-depth understanding of their lived experiences and circumstances (Creswell, 2013; Johnson \& Christensen, 2004). Participants' experiences are analyzed and compared to understand the essences of a particular phenomenon studied (Merriam \& Tisdell, 2016) — in this case, the adaptations of parentally bereaved youths.

Phenomenological analysis also requires the researchers to "bracket", or suspend, their biases in order to be open to the experience and to get to the essence of the phenomenon without judgement (Tufford \& Newman, 2010). Being aware of one's position is important in reducing a bias that may influence data collection and analysis (Daly, 2007). Like the participants in this study, the first author is a young adult who experienced the loss of a parent in adolescence. Her “insider" status facilitated participants' recruitment and promoted rapport during interviews. The second author contributed her "outsider" perspective to the topic, which was beneficial during research meetings and data analysis.

The beginning of the analysis process was inductive, as we attempted to search for categories and themes using pieces from the data (Merriam \& Tisdell, 2016). The first author read each transcript several times in order to fully grasp the data before beginning the analytical coding process (Merriam \& Tisdell, 2016). While rereading the transcripts, codes consisting of words and phrases in the data were assigned. Field notes and codes were studied and grouped for similarity. This process was repeated for all transcripts in order to verify whether the same codes were present in each previous transcript. The codes assigned throughout each transcript were then merged in order to create a primitive outline of recurring patterns in the study (Merriam \& Tisdell, 2016).

Emerging codes and themes were further explored in regular collaborative discussions with the second author. Both authors agreed that the themes that emerged from the data were closely linked to the factors within the Double ABC-X model. We therefore reviewed emerging codes and themes through the framework of the Double ABC-X model, identifying which factors from the model were represented in the data (e.g., aA, bB, X), which were less relevant (e.g., cC), and why. During discussions, we shared our perceptions of meanings behind the codes and themes, and whether the Double ABC-X model was reflective of the participants' reports of their families' adaptations post-crisis. A deductive mode was applied to data analysis until a sense of saturation was reached and we no longer found anything new (Merriam \& Tisdell, 2016). At the last step of 
International Journal of Child, Youth and Family Studies (2017) 8(3-4): 79-100

the analytical coding process, recurring patterns found in the transcripts were finalized into themes and aligned with the appropriate factors in the Double ABC-X model.

\section{Findings}

The findings of this study are presented using the Double ABC-X model of stress (McCubbin \& Patterson, 1983) that describes family adaptation post-crisis (see Figure 1). The death of a parent is conceptualized as the stressor event (A) for the participants. We will further describe the pile-up of stressors and the use of social support and coping strategies, and will conclude with a theme that describes participants' adaptation.

\section{Pile-up of Stressors Aggravates Grieving}

Following the death of a parent, participants and their family members were confronted with many daily changes and a pile-up of stressors that made grieving more difficult. Some of these stressors included financial issues, increased responsibilities, and complicated grief.

Financial issues: Families who lost their breadwinner had a difficult time coping with the death, as they also had the added stress of dealing with a financial burden. For example, Samar and his mother struggled financially following the death of his father and had to sell the house and relocate, "It was pretty hard, there were a lot of financial issues because there was nobody working in the house." The loss of the father meant that the role of provider had to be taken on by the mother. As several participants shared, mothers often became overwhelmed by new financial responsibilities and had difficulty fulfilling their other roles in the family. This also meant that adolescents had to take on household chores that were previously done by mothers. In contrast, participants whose families were financially secure spoke of having an easier time adjusting to the loss of a parent, as explained by Liam: "Knowing that you're still gonna go to school, everything is gonna be paid ... that helped us, and we were really able to focus on grieving."

Increased household responsibilities: The loss of a mother often meant that responsibilities related to the running of the household had to be picked up by fathers and children. Participants spoke about having to assume new responsibilities such as cooking, grocery shopping, laundry, and cleaning. Sofia shared, "The fridge was always empty, [my father] was never there. I would always have to do the groceries." Similarly, Daniel reported how the loss of his mother impacted his daily life in that he had to do a lot of housework at a young age, "There wasn't anybody to do the dishes or do my laundry, clean [the house] and put my clothes away, [take out] the garbage, grocery shopping." Those participants who lost the parent who was responsible for household chores found they had to spend more time on chores than previously. While some participants reported that their families worked together to adjust and split the burden of these responsibilities, others reported that they had little help from their surviving parent. 


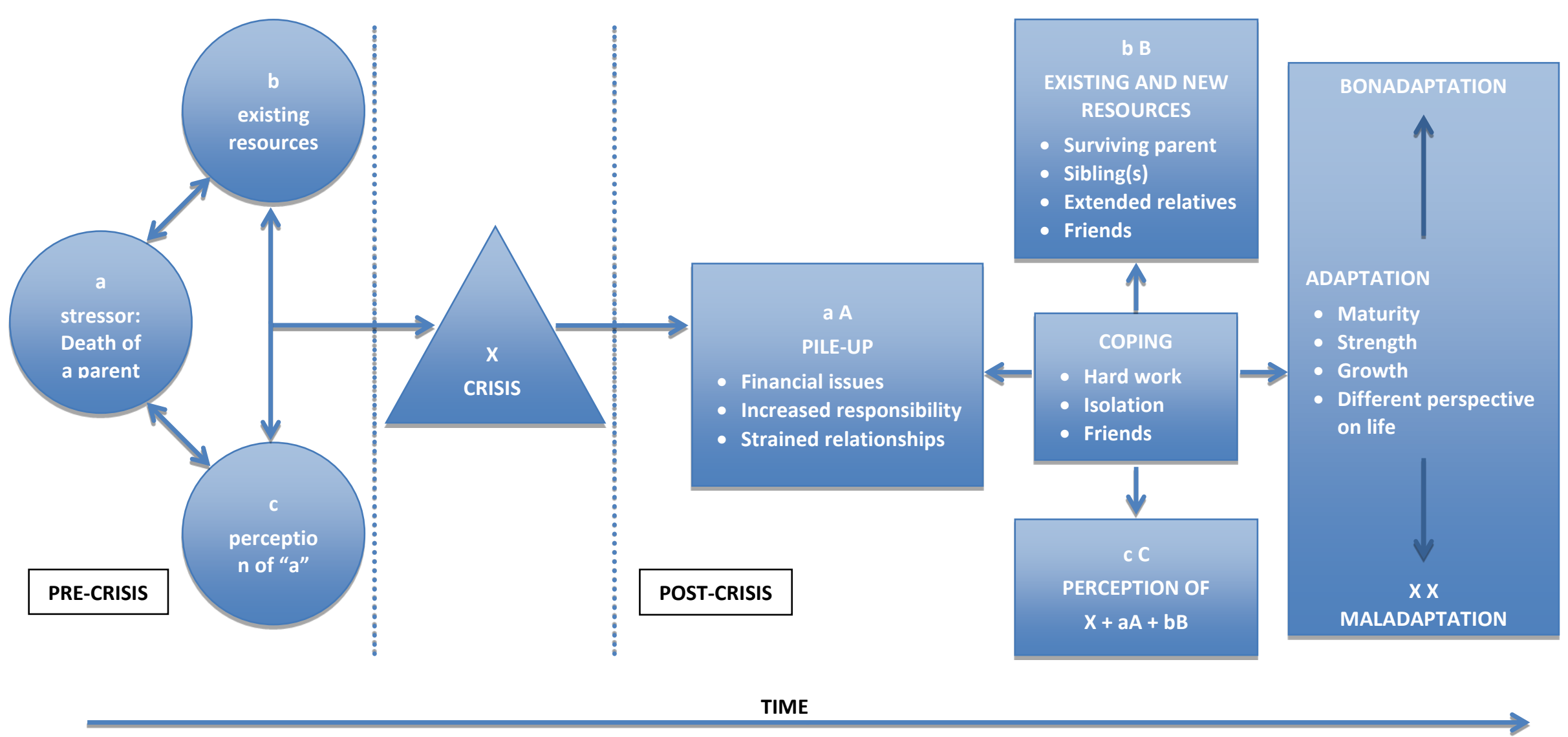

Figure 1. Adaptation of the Double ABC-X model for grieving families. 
International Journal of Child, Youth and Family Studies (2017) 8(3-4): 79-100

Complicated grief: Some participants said that their surviving parent was not a supportive resource to help them cope with the death. In a few cases, adolescents also had to assume the daunting responsibility of ensuring the safety of a widowed parent. For example, Juliette's mother became depressed after her husband's death and made several suicide attempts. Juliette was afraid to lose her mother and had to always be around her, which impacted her grieving experience: "The first three years we were not able to grieve because we were taking care of her." This burden did not allow Juliette and her brother to focus on their own grief or fully cope with the loss of their father; eight years later, she reports still grieving.

Overall, participants' narratives show that losing a parent who played a significant role in the household, and whom the family depended on emotionally and financially, had an important influence on the family's adaptation to the loss. The pile-up of financial, household, and emotional stressors made it harder for families to deal with their grief and sadness.

\section{Benefits of Social Support}

Participants reported that they needed a strong support system to help them cope with their loss. Main sources of support came from their immediate family members, extended relatives, and friends.

Surviving parent: The support of the surviving parent is crucial in helping children cope with and adjust to the loss of a parent. During the interviews, many participants spoke about strengths of their surviving parents who "kept it together" following the death. These young adults stated that because their widowed parents managed to maintain a certain level of normalcy and daily routine, and were emotionally supportive, they were able to cope with the loss and "move forward". In these cases, the experience of surviving the death resulted in stronger families that developed very close relationships: "[My mother and I] are really, really close, like partners, she likes to call it." At the same time, some families were crushed by the loss because they were incapable of communicating and finding support in each other following the death. Instead of uniting and supporting one another, they became distanced, as in the case of Akiko, whose relationship with her father became strained after her mother passed away: "We kind of stopped communicating ... we struggled for almost ten years." It was the loss of her father's mother years later that brought them together and helped them rebuild their relationship.

Siblings: It is common for siblings to become closer and lean on each other for support after the loss of a parent, especially if their surviving parent is unavailable or emotionally preoccupied. This was the case for several participants in the study, whose siblings became a source of support for each other following their parent's death. Their relationships got stronger because they shared a painful grieving experience. One said, "We are the only two people who actually understand what it's like to go through this kind of pain, so we have a strong bond."

Extended relatives: For the participants whose surviving parent and siblings were not available or helpful, their extended relatives became a source of support. For example, Daniel's 
International Journal of Child, Youth and Family Studies (2017) 8(3-4): 79-100

two sisters were living on their own at the time of their mother's passing away, and his father avoided his parental role. Daniel's aunt was the one who helped him on a regular basis by providing emotional and financial support; she made sure he had clothes and got to school to receive an education. He said, 'I don't know where I would be without [my aunt], because she's by far the most important person in my life."

Friends: Some participants, who lacked support from immediate family or extended relatives, found their friends to be very helpful in coping with the death of a parent. Molly shared that her brother was experiencing depression and her mother was dealing with financial issues and grieving the loss of her husband. As a family, they were unable to support each other emotionally. Molly found that support among her friends: "I had a lot of friends at the time, which was really helpful [then] and [continues to be helpful] even as life has gone."

All participants commented that they needed emotional support from someone to cope with their grief. If immediate family members were not available, then the support usually came from extended relatives or friends.

\section{Coping Strategies Used by the Participants}

After the loss of a parent, people develop coping mechanisms to help them grieve and cope with the loss. The main coping strategies described by the participants were working hard in school, using friends as a distraction, and isolating themselves when needed.

Focusing on schoolwork: Many of the participants used their academics as a coping outlet and a distraction from the loss; for many, the loss occurred during the time of their lives when grades were important for their future. When faced with the loss of a parent, something they had no control over, these adolescents turned to their schoolwork as something they could control. Participants spoke about focusing their energy on schoolwork, an outlet that allowed them to focus on something other than the pain of parental loss, as described by William: "I think one of my ways to sort of get my mind off things was just to work like crazy. I've never studied so hard as in that one, two years of my life." Focusing solely on his academics kept him distracted from the sad reality.

Friends as a distraction: Many participants reported using their friends as a distraction. Their friends provided fun and activities, which allowed the participants to take their minds off the death: "My grieving process is distraction. Just hanging out with friends, doing things I like to do, my hobbies and such." For many of the participants, spending time with their friends and peers in leisure was reported as a helpful coping strategy. They wanted to feel normal and not be viewed as outcasts. The death of a parent set them apart from most other students, so maintaining their friendships with a certain degree of normalcy was important and helpful.

Isolation to grieve on one's own: Several participants felt the need to isolate themselves from others, in order to grieve on their own. Although support was available to them, they chose 
International Journal of Child, Youth and Family Studies (2017) 8(3-4): 79-100

not to use it and instead coped using solitude, spirituality, or music. Lucas noted that his isolation was not unhealthy, as he accepted the fact that his mother was dead and he needed to cope and realize this on his own: "I kind of put up that wall where I didn't need anybody. I became a little more spiritual, found relief through good music. That was the way I dealt with it." Emma felt that she needed to cope with her loss on her own in order to be stronger: "If you're alone for a couple of weeks and you're feeling down, then it builds character in my opinion."

\section{Adaptation Following the Loss of a Parent: Personal Growth and Maturation}

An average of eight years had passed since the participants lost a parent. Although for some young adults in the study it was still difficult to talk about their loss, most reported that they had learned to live with it and had adapted well. A common theme ran through all of the participants' narratives: the first two years were the most difficult, but their loss had made them stronger, helped them gain maturity, and fostered a different perspective on life. Participants spoke about acquired resilience and personal growth: "Suffering makes you learn a lot about life, about yourself, about others, about everything — it makes you grow."

Participants equated the loss of a parent at a young age with the loss of their childhood. They felt that this experience pushed them into adulthood rapidly compared to peers who had not experienced such a tragedy. Children and adolescents who had lost a parent faced many challenges following the death and had to figure things out on their own, depending on the support they received from their surviving parent. Juliette spoke about how she lost her "life coach" the day her father passed away as he was an important figure who advised her and guided her in decisionmaking: "I became an adult the day he passed away. The two first years I was not able to take any decision because my father was my mentor. [In time I had to learn to make] my own decisions." Another participant spoke similarly about her mother: "It's hard because usually when you doubt, there's always your mom. [But] now there's no one to advise you."

Retrospectively, all participants felt that the death of their parents changed them, accelerating their maturation into adulthood. Losing a parent in childhood was an experience that also propelled these youths to change their perspective on life: "You kind of change your vision on life, you really try to enjoy the moment." The theme of maturity and growth as a result of surviving the death of a parent at a young age was prevalent in every single interview. Positive adaptation depended on many factors, such as availability and use of resources, coping strategies, and the pile-up of other stressors.

\section{Discussion}

This study explored the reflections of young adults on the experience of parental loss during adolescence. Personal interviews with in-depth, open-ended questions were used to allow the participants to reflect on how the death of a parent affected their families and how they coped with this loss. The themes that emerged from the data were consistent with the factors in the Double ABC-X model of family stress and adaptation (McCubbin \& Patterson, 1983): the pile-up of 
stressors following parental death (financial, household, and grief-related), use of social support (relationships with family, friends, and peers), and coping strategies (focusing on school, friends, or isolation). Generally, positive adaptation was reported by the participants, and was dependent on many factors, such as severity of the pile-up of other stressors, availability and use of social support resources, and a variety of coping strategies used by the participants.

The death of a parent is a tragic loss that is often followed by additional stressors in the family system, thus complicating each individual's journey through grief and bereavement. Many participants of the current study reported dealing with multiple stressors following a parent's death, such as changes in daily routines, increased responsibilities and household chores, financial difficulties, and relocation. Parentally bereaved adolescents often had to become responsible for many more household chores than they were used to. They also witnessed their surviving parent struggling with financial and other issues, which in turn created additional tension in the household. This situation made grieving more difficult for the surviving parent and children as the added stress overwhelmed them and prevented them from focusing on coping with their loss. These findings are consistent with previous research that found that a disruption of the daily environment after the death of a parent can make the grieving process more difficult for children (LaFreniere \& Cain, 2015; McClatchey \& Wimmer, 2012; Raveis et al., 1999; Worden, 1996).

A majority of the participants expressed the utmost importance of family or friends as sources of support. Consistent with previous research, all participants in this study relied on the surviving parent, siblings, friends, or extended relatives for emotional support to help them cope with the loss of a parent. The importance of the surviving parent's role in the post-death family environment in particular has long been established (Hope \& Hodge, 2006; Koblenz, 2015), and was evident in the interviews. Participants reported becoming closer with their only surviving parent, who offered open communication, security, a stable environment, and support, all of which are important for parentally bereaved children, as previous studies have found (Saldinger et al., 2004). At the same time, some participants were unable to rely on their surviving parent for emotional support due to strained relationships, and it took several years before their relationship with a surviving parent was mended.

If the surviving parent was not emotionally available, the participants turned to their siblings, extended relatives, or friends for support. Previous research on sibling relationships following the death of a parent was contradictory, with some concluding that it created distance between the siblings (Connidis, 1992; Scharlach \& Friedriksen, 1993), while others found that it strengthened sibling bonds (Hurd, 2002; Mack, 2004). The findings in the present study were consistent with the research demonstrating the benefit of having a sibling to share the experience of parental loss. Ten of the participants had siblings and most of them expressed the value of their sibling's support in working through their grief, which strengthened their sibling bond.

In terms of coping strategies helpful in times of grief, participants spoke about focusing their energy on academic achievements and working hard in school as well as using friends as a 
distraction, both of which allowed them to forget their loss for a time and feel "normal". These findings are consistent with previous studies that found seeking support from family and friends to be a positive and valuable coping strategy (Gray, 1989; Lawrence et al., 2005). Studies also found that an avoidant coping style, in which bereaved adolescents focus on other things in their lives, can be psychologically detrimental (Glyshaw et al., 1989). However, this coping style was effective for some of the participants in the study. Even though social support was available to them, a number of participants reported that they needed to grieve on their own. Thus, they found solitude, spirituality, or music to be helpful coping strategies (Lawrence et al., 2005); this is consistent with studies that have found spirituality to be beneficial for bereaved children and adolescents' coping and meaning-making (Holder, Coleman, \& Wallace, 2010).

Previous research found that children may become resilient after the loss of a parent, but it depends on various factors such as constant communication, especially about the death, support from family and friends, and a stable environment (Greeff \& Human, 2004; Hope \& Hodge, 2006; LaFreniere \& Cain, 2015; Raveis et al., 1999). Many participants expressed that losing a parent was like losing their guide, which accelerated their growing up and forced them to make decisions on their own. All participants stated that the traumatic experience of losing a parent contributed to their personal growth, maturity, and the development of a new perspective on life. Many relied on some form of support system after the death, whether it was their surviving parent, siblings, friends, or extended relatives, a finding consistent with research on resilience (Greeff \& Human, 2004). The Double ABC-X model helped organize the themes and provided a visual aid to understanding the process bereaved children go through as they grieve over their parent's death and adapt to a new reality.

\section{Limitations}

This study was based on a small sample of individuals who chose to participate and thus may have been more open to talking about their experiences or had an easier time adjusting to the death than those who did not participate. Also, the experiences of these college-educated young adults may differ from those who have not attended college.

The participants in this study lost a parent due to different causes - some to a long-term illness, others to a sudden heart attack. The differences in whether the death was sudden or anticipated may have complicated the mourning process for some, but this was not brought up by the participants during the interviews. Another limitation of this study is that some of the participants had trouble reflecting on their relationships prior to and following the death of their parent, as some were young and several years had passed since the event.

Finally, one of the initial intentions of this study was to explore the impact of milestone events (e.g., graduation, marriage, having children) to find out whether they triggered any grief responses. Some participants anticipated that getting married and having children would be difficult events without their deceased parent, and some shared that special events such as birthdays and holidays were emotionally trying. However, due to the young age of the participants 
that were recruited, little information about the grief responses during milestone events such as marriage and parenthood emerged. Future studies may be able to explore the impact of milestone events by recruiting participants who are older than 30 years of age and who are married and have children.

\section{Implications}

Research in the area of grief can aid families and practitioners in creating intervention strategies to help deal with the pile-up of stressors that may occur after a death, as well as strategies to help individuals and families cope with the loss. Parentally bereaved families should be encouraged to focus on building open communication and supportive parent-child and sibling relationships. Participating in grief camps or group therapy can be valuable for bereaved children as it allows them to relate to other children who have lost a parent (Koblenz, 2015; McClatchey \& Wimmer, 2012). Future research should explore other important resources and coping strategies that may facilitate positive adaptation following the loss of a parent. 
International Journal of Child, Youth and Family Studies (2017) 8(3-4): 79-100

\section{References}

Biank, M. N., \& Werner-Lin, A. (2011). Growing up with grief: Revisiting the death of a parent over the life course. Omega: Journal of Death and Dying, 63(3), 271-290. doi:10.2190/OM.63.3.e

Boss, P. (2002). Family stress management: A contextual approach. Thousand Oaks, CA: Sage.

Bugge, K. E., Darbyshire, P., Rokholt, E. G., Haugstvedt, K. S., \& Helseth, S. (2014). Young children's grief: Parents' understanding and coping. Death Studies, 38(1), 36-43. doi:10.1080/07481187.2012.718037

Connidis, I. A. (1992). Life transitions and the adult sibling tie: A qualitative study. Journal of Marriage and the Family, 54, 972-982. doi:10.2307/353176

Creswell, W. J. (2013). Qualitative inquiry and research design: Choosing among five approaches. Thousand Oaks, CA: Sage.

Daly, K. J. (2007). Qualitative methods for family studies and human development. Thousand Oaks, CA: Sage.

Dopp, A. R., \& Cain, A. C. (2012). The role of peer relationships in parental bereavement during childhood and adolescence. Death Studies, 36, 41-60. doi:10.1080/07481187.2011.573175

Edelman, H. (1994). Motherless daughters: The legacy of loss. New York, NY: Dell.

Eppler, C. (2008). Exploring themes of resiliency in children after the death of a parent. Professional School Counseling, 11(3), 189-196.

Gimenez, L., Chou, S., \& Liu, J.-T., \& Liu, J.-L. (2013). Parental loss and children's well-being. Journal of Human Resources, 48(4), 1035-1071. doi:10.3368/jhr.48.4.1035

Glyshaw, K., Cohen, L., \& Towbes, L. (1989). Coping strategies and psychological distress: Prospective analyses of early and middle adolescents. American Journal of Community Psychology, 17(5), 607-623. doi:10.1007/BF00922638

Gray, R. E. (1989). Adolescents' perceptions of social support after the death of a parent. Journal of Psychosocial Oncology, 7(3), 127-144. doi:10.1300/J077v07n03_09

Greeff, P. A., \& Human, B. (2004). Resilience in families in which a parent has died. The American Journal of Family Therapy, 32(1), 27-42. doi:10.1080/01926180490255765

Herman-Stahl, M., Stemmler, M., \& Petersen, A. (1995). Approach and avoidant coping: Implications for adolescent mental health. Journal of Youth and Adolescence, 24(6), 649665. doi:10.1007/BF01536949 
International Journal of Child, Youth and Family Studies (2017) 8(3-4): 79-100

Hill, R. (1958). Generic features of families under stress. Social Casework, 49(2-3), 139-150.

Holder, M. D., Coleman, B., \& Wallace, J. M. (2010). Spirituality, religiousness, and happiness in children aged 8-12 years. Journal of Happiness Studies, 11(2), 131-150. doi:10.1007/s10902-008-9126-1

Hollingshaus, M. S., \& Smith, K. R. (2015). Life and death in the family: Early parental death, parental remarriage, and offspring suicide risk in adulthood. Social Science \& Medicine, 13(1), 181-189. doi:10.1016/j.socscimed.2015.02.008

Hope, M. H., \& Hodge, M. D. (2006). Factors affecting children's adjustment to the death of a parent: The social work professional's viewpoint. Child and Adolescent Social Work Journal, 23(1), 107-126. doi:10.1007/s10560-006-0045-x

Howell, K. H., Shapiro, D. N., Layne, C. M., \& Kaplow, J. B. (2015). Individual and psychosocial mechanisms of adaptive functioning in parentally bereaved children. Death Studies, 39(5), 296-306. doi:10.1080/07481187.2014.951497

Hurd, C. R. (2002). Sibling support systems in childhood after a parent dies. Omega: Journal of Death and Dying, 45(4), 299-320. doi:10.2190/B92T-LPQR-1RP9-9562

Jacobs, S., Hansen, F., Kasl, S., Ostfeld, A., Berkman, L., \& Kim, K. (1990). Anxiety disorders during acute bereavement: Risk and risk factors. Journal of Clinical Psychiatry, 51, 269274.

Johnson, S., \& Christensen, L. (2004). Educational research: Quantitative, qualitative, and mixed approaches. Boston, MA: Pearson.

Kaplow, J. B., Gipson, P. Y., Horwitz, A. G., Burch, B. N., \& King, C. A. (2013) Emotional suppression mediates the relation between adverse life events and adolescent suicide: Implications for prevention. Prevention Science 15(2), 177-185. doi:10.1007/s11121-013$\underline{0367-9}$

Koblenz, J. (2015). Growing from grief: Qualitative experiences of parental loss. Omega: Journal of Death and Dying, 73(3), 203-230. doi:10.1177/0030222815576123

LaFreniere, L., \& Cain, A. (2015). Parentally bereaved children and adolescents: The question of peer support. Omega: Journal of Death and Dying, 71(3). 245-271.

doi: $10.1177 / 0030222815575503$

Lawrence, E., Jeglic, E. L., Matthews, L. T., \& Pepper, C. M. (2005). Gender differences in grief reactions following the death of a parent. Omega: Journal of Death and Dying, 52(4), 323337. doi:10.2190/55WN-1VUF-TQ3W-GD53 
International Journal of Child, Youth and Family Studies (2017) 8(3-4): 79-100

Mack, Y. K. (2004). The effects of early parental death on sibling relationships in later life. Omega: Journal of Death and Dying, 49(2), 131-148. doi:10.2190/BTUQ-011V-ANEWV7RT

Masten, A. S., \& Powell, J. L. (2003). A resilience framework for research, policy, and practice. In S. S. Luthar (Ed.), Resilience and vulnerability: Adaptation in the context of childhood adversities (pp. 1-25). New York, NY: Cambridge University Press.

McClatchey, I. S., \& Wimmer, J. S. (2012). Coping with parental death as seen from the perspective of children who attended a grief camp. Qualitative Social Work, 13(2), 221236. doi: $10.1177 / 1473325012465104$

McCubbin, I. H., \& Patterson, M. J. (1983). Family transitions: Adaptation to stress. In H. I. McCubbin \& C. R. Figley (Eds.), Stress and the family (pp. 5-25). New York, NY: Brunner/Mazel.

MediResource. (2017). Suicide. Retrieved from http://www.medbroadcast.com/condition/getcondition/suicide

Merriam, B. S., \& Tisdell, J. E. (2016). Qualitative research: A guide to design and implementation. San Francisco, CA: Jossey-Bass.

Pfeffer, C. R., Jiang, H., Kakuma, T., Hwang, J., \& Metsch, M. (2002). Group intervention for children bereaved by the suicide of a relative. Journal of the American Academy of Child Adolescent Psychiatry, 41(5), 505-513. doi:10.1097/00004583-200205000-00007

Raveis, H. V., Siegel, K., \& Karus, D. (1999). Children's psychological distress following the death of a parent. Journal of Youth and Adolescence, 28(2), 165-180. doi:10.1023/A:1021697230387

Ross. H. G., \& Milgram, J. I. (1982). Important variables in adult sibling relationships: A qualitative study. In M. E. Lamb \& B. Sutton-Smith (Eds.), Sibling relationships: Their nature and significance across the lifespan (pp. 225-249). Hillsdale, NJ: Lawrence Erlbaum Associates.

Saldinger, A., Porterfield, K., \& Cain, A. C. (2004). Meeting the needs of parentally bereaved children: A framework for child-centered parenting. Psychiatry, 67, 331-352. doi: $10.1521 /$ psyc.67.4.331.56562

Saler, L., \& Skolnick, N. (1992). Childhood parental death and depression in adulthood: Roles of surviving parent and family environment. American Journal of Orthopsychiatry, 62(4), 504-516. doi:10.1037/h0079372 
International Journal of Child, Youth and Family Studies (2017) 8(3-4): 79-100

Scharlach, A. E., \& Fredriksen, K. I. (1993). Reactions to the death of a parent during midlife. Omega: Journal of Death and Dying, 27(4), 307-319. doi:10.2190/N2GW-N9WE-UEUP9H4D

Schoenfelder, E. N., Sandler, I. N., Wolchik, S., \& MacKinnon, D. (2011). Quality of social relationships and the development of depression in parentally-bereaved youth. Journal of Youth and Adolescence, 40(1), 85-96. doi:10.1007/s10964-009-9503-z

Silverman, R. P., \& Worden, W. J. (1992). Children's reactions in the early months after the death of a parent. American Orthopsychiatric Association, 62(1), 93-104. doi:10.1037/h0079304

Statistics Canada. (2015). Living arrangements of children in Canada: A century of change [Online catalogue no. 75-006-X]. Ottawa, ON: Statistics Canada. Retrieved from https://www.statcan.gc.ca/pub/75-006-x/2014001/article/11919-eng.htm

Statistics Canada. (2016). Portrait of children's family life in Canada in 2016 [Census in brief]. Ottawa, ON: Statistics Canada. Retrieved from http://www12.statcan.gc.ca/censusrecensement/2016/as-sa/98-200-x/2016006/98-200-x2016006-eng.cfm

Tufford, L., \& Newman, P. A. (2010). Bracketing in qualitative research. Qualitative Social Work, 11(1), 80-96. doi:10.1177/1473325010368316

Ungar, M. (2008). Resilience across cultures. The British Journal of Social Work, 38(2), 218235. doi:10.1093/bjsw/bcl343

Walsh, F., \& McGoldrick, M. (2004) Living beyond loss: Death in the family. New York, NY: W. W. Norton \& Company.

Worden, J. W. (1996). Children in grief: When a parent dies. New York, NY: Gilford Press. 
International Journal of Child, Youth and Family Studies (2017) 8(3-4): 79-100

\section{Appendix}

\section{Interview Guide}

1. How did your relationship with your sibling(s) change after the death of your parent? Did your relationship(s) get stronger? Or did the death create a distance between you and your sibling(s)?

a. Do you feel like you can talk to your sibling(s) about the death of your parent? If so, has that helped you grieve in any way?

b. (For those who have no siblings) If you had had a sibling, how do you think this could have changed your grieving process? Did you miss having someone other than your parent to talk to and confide in?

2. Explain how your social network helped you through your grieving process (relatives, friends, teachers/professors, and/or therapists).

3. How would you say your relationship with your surviving mother/father was impacted?

a. Do you think your surviving parent has helped you grieve? If so, how?

b. Can you talk to your surviving parent about the death?

4. Please explain any daily changes you experienced after the death of your parent (relocation, financial issues, increased responsibility/chores, emotions).

a. Did you find this difficult? Or did it help you with your grieving process?

5. What milestone events have occurred in your life since your parent passed away (graduation, marriage, career/job, baby, moving out, birthdays, anniversaries, holidays)?

a. Did it make you feel like you were grieving again? Did it make you think about your parent? Did you wish he/she was there with you in this important moment? How did these moments make you feel?

6. How do you think the death of your parent has changed you?

a. Has it made you stronger or weaker?

b. What advice would you give to other children going through this? What would you say helped you the most? 